\title{
Dietary Iron Source and Lung Cancer Risk: A Case-Control Study in Uruguayan Men
}

DOI: 10.30699/acadpub.mci.3.3.20

\author{
Alvaro L. Ronco ${ }^{1,2,3, *}$, Eduardo Lasalvia-Galante ${ }^{2}$, Juan M. Calderón ${ }^{3}$, \\ Edison Espinosa ${ }^{3}$ \\ ${ }^{I}$ Unit of Oncology and Radiotherapy, Pereira Rossell Women's Hospital, Bvar. \\ Artigas 1590, Montevideo 11600, Uruguay \\ ${ }^{2}$ School of Medicine, CLAEH University, Prado and Salt Lake, Maldonado 20100, \\ Uruguay \\ ${ }^{3}$ Biomedical Sciences Center, University of Montevideo, Puntas de Santiago 1604, \\ Montevideo 11500, Uruguay \\ *Corresponding author: Alvaro L. Ronco, Convención 1490 dept.202, Montevideo 11100, \\ Uruguay. Tel: +59899431787; Fax: +59827075317; E-mail:alv.ronco58@gmail.com
}

Submitted: 28 April 2019

Revised: 26 May 2019

Accepted: 13 June 2019

e-Published: 1 July 2019

\section{Keywords:}

Diet

Heme

Ilex paraguariensis

Iron

Lung Neoplasms

Non-Heme Iron

Introduction: Iron metabolism was found to be implicated in several cancers. Few epidemiologic studies; focusing on iron intake and lung cancer (LC), reported positive associations between heme iron and red meat. Based on estimates of iron contents in representative foods, we conducted the present study with the aim of analyzing dietary iron and its role on the incidence of LC in Uruguayan men, since this population has the highest meat intake worldwide.

Methods: A case-control study was performed on 843 LC cases and 1466 controls; using a specific multi-topic questionnaire including a food frequency questionnaire. This matched case-control study was designed according to age-frequency, urban/rural residence, and country region. Food-derived nutrients were calculated from available databases. Total dietary iron was calculated according to its animal, plant, heme and non-heme source after being adjusted by energy. Odds Ratios (ORs) were estimated by logistic regression; being adjusted for potential confounders.

Results: Iron intake was associated with $\mathrm{LC}$ risk. Total $(\mathrm{OR}=3.26)$, animal $(\mathrm{OR}=3.73)$, heme $(\mathrm{OR}=2.94)$, and animal non-heme $(\mathrm{OR}=3.15)$ iron were positively associated with $\mathrm{LC}$; whereas plant $(\mathrm{OR}=0.66)$ and non-heme fraction in total iron $(\mathrm{OR}=0.56)$ were inversely associated with LC incidence. Risks were very similar for all histological types of tumors. In addition, stratified analyses showed higher ORs for intense smokers and intense "maté" drinkers.

Conclusions: The source and proportions of dietary iron might be of importance as a link to lung carcinogenesis; suggesting that low intakes of animal sources and high consumption of plant sources could be healthier. Further studies are needed to clarify this point.

(C) 2019. Multidisciplinary Cancer Investigation

\section{INTRODUCTION}

Lung cancer (LC) has been the most frequent malignancy in Uruguayan men but it is currently occupying the $2^{\text {nd }}$ place of incidence after prostate cancer [1]. However, the adjusted incidence rate $(\sim 47 / 100.000$ men) in the Uruguayan men population is still at top of the list in America which is slightly lower than West and South Europe [2]. Although smoking is elsewhere the major risk factor of LC ( $85 \%$ of attributable risk [3]), diet is also considered as a potentially modifiable 
risk factor [4]. This fact has been analyzed in Uruguayan studies along the last two decades [57]. The Uruguayan average diet is meat-based, with the world's highest per capita beef intake [8]. Red and processed meat have been implicated in lung carcinogenesis which has been attributed to some of their components (own or added ones) as fats, cholesterol, heterocyclic amines (HCA), nitrosodimethylamine, iron, etc. [9]. A metaanalysis suggested that a high red meat intake may increase LC risk even among non-smokers [10]. Iron is essential for many biological processes, however, too much or too little iron can derive into a wide variety of pathological consequences, depending on the affected tissue or cell type. Iron balance is achieved by careful control of its intake and recycling [11]. The approximate percentage of heme and non-heme iron absorbance is $30 \%$ and $10 \%$, respectively [12].

Because humans lack a mechanism for controlled iron excretion, regulation of body iron content ( $\sim 4$ $\mathrm{g}$ in adults) depends on the control of dietary iron absorption [13]. Regulatory systems; controlling iron absorption, systemic transport, and cellular uptake and storage enable the body to control iron levels [14]. Iron accumulation during lifespan is potentially disadvantageous for men, because women experience periodical iron loss with their menses during the reproductive years, something that could operate as a balancing system against a dietary iron excess. Even both sexes could share similar dietary styles, different body iron levels might be expected near the age of 50 .

Altered iron levels and/or dysregulated homeostasis have been associated with several lung diseases, including chronic obstructive pulmonary disease (COPD), LC, and asthma [15]. In particular, iron intake is associated with carcinogenesis aspects such as the formation of endogenous $\mathrm{N}$-nitroso compounds and an increase in the oxidative stress [16]. Iron overload induces free radical formation, lipid peroxidation, DNA and protein damages; while iron metabolism plays a key role in epigenetic regulation of cancer cells [17]. In addition, higher body iron which is represented by higher iron and ferritin levels may be associated with cancer risk [18] and particularly with LC incidence [19]. Nevertheless, recent evidence on iron load does not support a higher risk of LC [20, 21].

We have recently evaluated the proportions of dietary iron according to its sources and subtypes, and its possible association with breast cancer risk $[22,23]$. These studies reported epidemiologic evidence of an animal/plant ratio [22] as well as a heme/non-heme ratio [23] of dietary iron in support of a direct association to the disease. Besides, only a few epidemiologic studies (all of them conducted in North American and European populations) have been published on the role of heme iron in LC risk [24-30]. Most of them tended to display a risk elevation by increasing heme iron intake.

Uruguayans are the world's highest "maté" consumers $(9-10 \mathrm{~kg} /$ person/year of the herb and $\sim 400$ liters/person/year of infusion) and more than $80 \%$ of inhabitants are "maté" drinkers [31]. "Maté" is the name of the infusion made from the Ilex paraguariensis herb, and according to International Agency for Research on Cancer, hot "maté" drinking is considered as a $2 \mathrm{~A}$ agent (possibly carcinogenic for humans) [32]. High levels of several carcinogenic polycyclic aromatic hydrocarbons (PAH) were found in this drink $[33,34]$. Phenanthrene and benzo[a]pyrene $(\mathrm{BaP})$ that are found in both hot and cold "maté" [34], are considered as carcinogens to humans [35]. "Maté" intake was found positively associated with an increase in LC risk in the first evaluations [36]. Associations were significant for the amount (liters/day) and intensity (liters $\times$ years) of its consumption. A further multi-site study confirmed a positive association with intense "maté" intake and the incidence of LC [37]. Unlike cancers of the upper digestive tract origin (which has direct contact to the hot infusion), it was considered that LC may represent a good model for testing a chemical rather than a thermal effect of "maté".

Although Uruguay is a developing country, its population has a meat-based and western dietary style. Historically, livestock and meat production have been strongly related to Uruguay which is closely related to an early introduction of cattle even before European settlers landed. Livestock production became the most important economic activity and export product at least two centuries ago, leading meat to be reflected as traditional lowcost food.

The aforementioned epidemiologic links among iron, red/processed meat, "maté", and LC, justified doing additional studies in this regards. Therefore, we considered conducting a case-control study on 
dietary iron and LC risk by applying a similar data analysis methodology as in our previous research and making special efforts in order to control for potential confounders such as smoking which is an important aspect in the diet-LC analyses. To our knowledge, this is the first Latin American epidemiologic study exploring possible roles of dietary iron and LC risk.

\section{METHODS}

\section{Selection of Cases and Controls}

As a part of a multi-site epidemiologic research, during the study period (1996-2004), all newly diagnosed and microscopically confirmed cases of LC in men were considered eligible for this study. These cases were drawn from the four major public hospitals of Montevideo and Uruguay (Clinicas University hospital, Maciel, Pasteur, and Oncology Institute) which catch a large fraction of patients from the public system for diagnosis and/ or treatment of cancer. The public health system is centralized in Montevideo where less than 50\% of the country population lives; while more than $50 \%$ of total cancer cases are diagnosed. In this period, 896 LC cases were identified from who, 20 patients refused the review, and a total of 876 cases were remained to be included in the study (response rate $97.8 \%$ ). Of them, 33 cases did not complete the questionnaire, delivering then a final number of 843 cases. Patients distribution by cancer cell type was as follows: squamous cell (300 patients, $35.6 \%$ ), adenocarcinoma (186, 22.1\%), small cell carcinoma $(88,10.4 \%)$, other types including large cell carcinoma and malignancies not otherwise specified (195, 23.1\%), and unclassified (74, 8.8\%). In the same time period and the same hospitals, all male patients hospitalized for conditions not related to tobacco smoking or alcohol drinking and without recent changes in their diets were considered eligible to be considered as the control group for the study. One thousand and five hundred thirtyfour $(1,534)$ patients were considered eligible. Forty (40) patients refused the interview leaving 1,494 patients as potential controls (response rate $97.4 \%$ ). From these potential controls, 1466 patients completed the questionnaire and were included in the study. Controls were matched to cases with regards to age (10-year groups), residence (urban/rural), and region (Montevideo/ Other counties). Controls were classified as follows: abdominal hernia (292 patients, 19.9\%), bone diseases $(280,19.1 \%)$, eye disorders $(258$, $17.6 \%)$, skin diseases $(148,10.1 \%)$, injuries $(138$, $9.4 \%)$, appendicitis $(89,6.1 \%)$, varicose veins $(78$, $5.3 \%)$, urinary stones $(66,4.5 \%)$, hydatid cyst (48, $3.3 \%$ ), prostate hypertrophy $(47,3.2 \%)$, and blood disorders $(22,1.5 \%)$.

The planned study expected to obtain 2 matched controls per case. Regarding the correlation between exposure rates for case and controls, since prior data were not easily available, we followed what Dupont [38] suggested, assuming a value of 0.2 . With a theoretical $\mathrm{OR}=2.5$ for disease in exposed/unexposed individuals, we needed at least 406 cases with 2 matched controls per case to reject the null hypothesis with a power $=0.80$ and with an $\alpha$-error $=0.05[39,40]$.

Trained social workers interviewed patients in the hospitals shortly after admittance without proxy interviews. Patients admitted to public hospitals were people with low incomes coming from all around the country and had free access to most medical services as a mandatory law of Uruguay. According to the features of the population, they were good representatives of a third world country, different from the population being admitted at the private health subsystem. We have not excluded any participants as outliers for iron or other dietary components.

\section{Questionnaire}

Participants answered a structured questionnaire which included socio-demographic variables including occupation, cancer history in the $1^{\text {st }}$ - and $2^{\text {nd }}$-degree relatives, self-reported height and weight 5 years before the interview, smoking and alcohol consumption, and history of "maté", tea and coffee drinking. A food frequency questionnaire (FFQ) containing 64 items that were representative of the Uruguayan diet and focused on food consumption during the last 5 years was also completed. Proxy interviews were not accepted. The FFQ was not validated but was tested for reproducibility [41]; allowing individual energy estimation. All dietary questions were open-ended. Local tables of food composition were used for estimating energy and nutrients [42].

Smoking habit was evaluated by 8 items: smoking status (No smoker, Ex-, Current), amount ( $\mathrm{N}^{\circ}$ of cigarettes/day), type (blond, mixed, black), rolling (manufactured, hand-rolled), age at start, age at quit, 
duration (age at quit - age at start), and intensity (pack-years, $=$ the product of calculated packs of 20 units smoked per day $\times$ smoking duration in years). Patients who reported quitting within the same year of their interview were considered as current smokers.

\section{Estimation of Iron and Nutrients Intake}

We estimated heme iron intake; using FFQ according to the previous dietary studies [4345]. Heme iron was estimated by calculating its percentage of total iron in the following foods: $69 \%$ for beef, $39 \%$ for ham, bacon, mortadella, salami, hot dogs, saucisson and sausage, $26 \%$ for chicken, fish, eggs, and milk, and $21 \%$ for the liver. We calculated mean daily heme iron intake by multiplying consumption frequency by amount of total iron and the quoted percentages. Nonheme iron intake was calculated by subtracting heme iron intake from total iron. Animal-based iron was calculated by addition of estimations from all animal foods; plant-based iron derived from subtracting animal-based iron from total iron. The so-called fractions were obtained as a percentage of total iron [23]. For the present study, we estimated the non-heme component of animal iron by using the below-mentioned formula: Animal non-heme iron=animal iron-heme iron.

For analysis purposes and based on the original iron variables, an Animal/Plant iron ratio (APIR) and a Heme/Non-Heme ratio $(\mathrm{H} / \mathrm{NH})$ were assumed. In order to calculate energy and daily nutrients, an analysis program was compiled which made the sum of all individual values. Accordingly, the number of servings/year was multiplied by the ratio nutrient content or calories of the serving/100 $\mathrm{g}$ of each individual, divided by 365 days. The typical average servings of solid foods are within the normal range of 100-150 g. Since iron intake showed a high correlation with energy, we calculated an iron density expressed as daily $\mathrm{mg}$ of the mineral $/ \mathrm{kcal} \times 1000$.

\section{Statistical Analysis}

Most questionnaire variables were originally continuous; when necessary, they were categorized for analysis purposes. In order to select variables to be entered in further regressions, preliminary univariate analyses (chi-square tests) were performed on a series of numerical variables of the database which were previously found to have some prognostic value for cancer risk estimation. Selected interest variables were presented as mean values \pm standard deviation (SD).

In order to analyze the association between exposure levels of iron types and LC, we estimated ORs and $95 \%$ confidence intervals $(95 \% \mathrm{CI})$ for each interest variable which were calculated by unconditional logistic regression [39], adequate for the matching design based on few socio-demographic variables. The dependent variable was cancer (binary, yes/ no). Reported $\mathrm{p}$-values were two-sided and $\mathrm{P}<0.05$ were considered statistically significant. Potential confounders were included in the multivariate analyses.

Independent variables included age, residence, education, body mass index (BMI), family history of cancer in $1^{\text {st }}$-degree relatives, energy intake, total meat intake, total plants intake, total fibre intake, calcium intake, "maté" intake, alcohol consumption, and a detailed list of smoking variables (smoking status, cigarettes amount, tobacco type, cigarette manufacturing, age at start, age at quit, duration of habit, and pack-years). Calculations were done with STATA software (Release 10, Stata Corp LP, College Station, TX, 2007).

\section{RESULTS}

Table 1 shows the distribution of cases and controls according to the selected variables. Due to the study design, urban/rural status and residence region (Montevideo/Other) had similar proportions in both groups. Although participants were not completely matched, no significant differences were achieved in terms of age distribution $(\mathrm{P}=0.22)$. Education periods were rather similar. Cases tended to display lower BMI than controls. On the other hand, cases had a significantly higher number of $1^{\text {st }}$-degree relatives with cancer as well as a higher numberof current smokers and current alcohol and "maté" drinkers.

Selected nutritional variables were analyzed and presented as mean values \pm SD in Table 2. All iron variables (12) displayed statistically significant differences between cases and controls. Higher mean daily intakes (expressed in $\mathrm{mg} / 1000 \mathrm{kcal}$ ) of total iron (4.16 vs. 3.79), animal-based iron (3.30 vs. 2.83 ), heme iron (1.99 vs. 1.69), total non-heme iron (2.17 vs. 2.09), and animal-based non-heme iron (1.31 vs. 1.14) were found among LC cases 
Table 1: Distribution of Cases and Controls

\begin{tabular}{|c|c|c|c|c|}
\hline & Controls, No.(\%) & Cases, No.(\%) & Total, No.(\%) & P Value \\
\hline Age Groups, y & & & & 0.220 \\
\hline$\leq 49$ & $196(13.4)$ & $112(13.3)$ & $308(13.3)$ & \\
\hline $50-59$ & $250(17.0)$ & $171(20.3)$ & $421(18.2)$ & \\
\hline $60-69$ & $560(38.2)$ & $326(38.7)$ & $886(38.4)$ & \\
\hline $70-79$ & $413(28.2)$ & $213(25.3)$ & $626(27.1)$ & \\
\hline$\geq 80$ & $47(3.2)$ & $21(2.5)$ & $68(2.9)$ & \\
\hline Residence & & & & 0.970 \\
\hline Urban & $1128(76.9)$ & $648(76.9)$ & $1776(76.9)$ & \\
\hline Rural & $338(23.1)$ & $195(23.1)$ & $533(23.1)$ & \\
\hline Living Region & & & & 0.960 \\
\hline Montevideo & $718(49.0)$ & $412(48.9)$ & $1130(48.9)$ & \\
\hline Other sites & $748(51.0)$ & $431(51.1)$ & $1179(51.1)$ & \\
\hline Education Years & & & & 0.680 \\
\hline$\leq 2$ & $389(26.5)$ & $227(26.9)$ & $616(26.7)$ & \\
\hline $3-4$ & $417(28.4)$ & $257(30.5)$ & $674(29.2)$ & \\
\hline $5-6$ & $486(33.1)$ & $264(31.3)$ & $750(32.5)$ & \\
\hline$\geq 7$ & 174(11.9) & $95(11.3)$ & $269(11.6)$ & \\
\hline Family History of Cancer in $1^{\text {st }}$ Degree & & & & $<0.001$ \\
\hline None & $1088(74.2)$ & $548(65.1)$ & $1636(70.8)$ & \\
\hline 1 & $324(22.1)$ & $248(29.4)$ & $572(24.8)$ & \\
\hline$\geq 2$ & $54(3.7)$ & $47(5.6)$ & 101(4.4) & \\
\hline Body Mass Index, kg/m² & & & & $<0.001$ \\
\hline$\leq 18.49$ & $21(1.4)$ & $17(2.0)$ & $38(1.7)$ & \\
\hline $18.5-24.99$ & $721(49.2)$ & $498(59.1)$ & $1219(52.8)$ & \\
\hline $25.0-29.99$ & $582(39.7)$ & 252(29.9) & $834(36.1)$ & \\
\hline$\geq 30.0$ & 142(9.7) & $76(9.0)$ & $218(9.4)$ & \\
\hline Smoking Status & & & & $<0.001$ \\
\hline Non Smoker & $282(19.2)$ & $17(2.0)$ & 299(12.9) & \\
\hline Ex-Smoker & $520(35.5)$ & $223(26.4)$ & $743(32.2)$ & \\
\hline Curr.Smoker & $664(45.3)$ & $603(71.6)$ & $1267(54.9)$ & \\
\hline Alcohol Status & & & & $<0.001$ \\
\hline Non Drinker & $407(27.8)$ & $165(19.6)$ & $572(24.8)$ & \\
\hline Ex-Drinker & $236(16.1)$ & $141(16.7)$ & $377(16.3)$ & \\
\hline Curr.Drinker & $823(56.1)$ & $537(63.7)$ & $1360(58.9)$ & \\
\hline Maté a Status & & & & $<0.001$ \\
\hline Non Drinker & $179(12.2)$ & $41(4.9)$ & $220(9.5)$ & \\
\hline Ex-Drinker & $85(5.8)$ & $42(5.0)$ & $127(5.5)$ & \\
\hline Curr.Drinker & $1202(82.0)$ & $760(90.1)$ & $1962(85.0)$ & \\
\hline Total patients & $1466(100.0)$ & $843(100.0)$ & $2309(100.0)$ & \\
\hline
\end{tabular}

${ }^{a}$ Maté is the name of the staple infusion in Uruguay, made from the Ilex paraguariensis herb. 


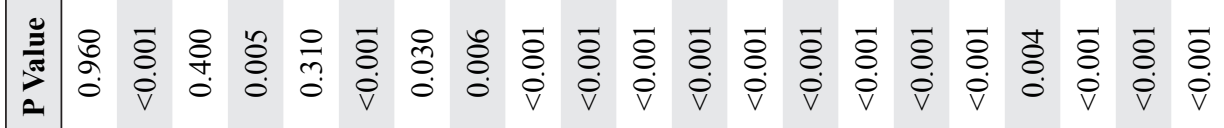

की

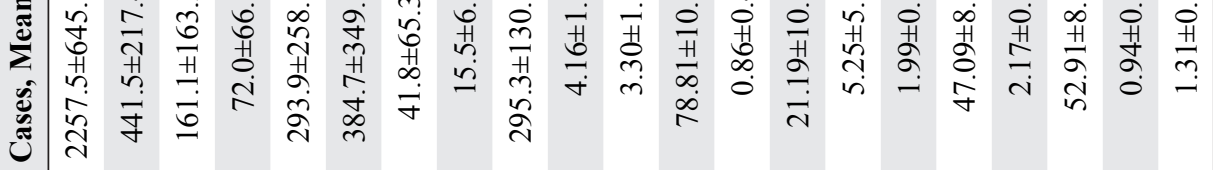

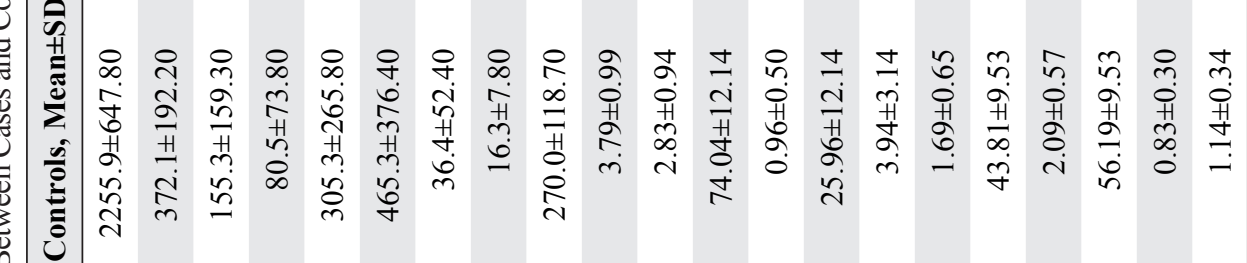
.

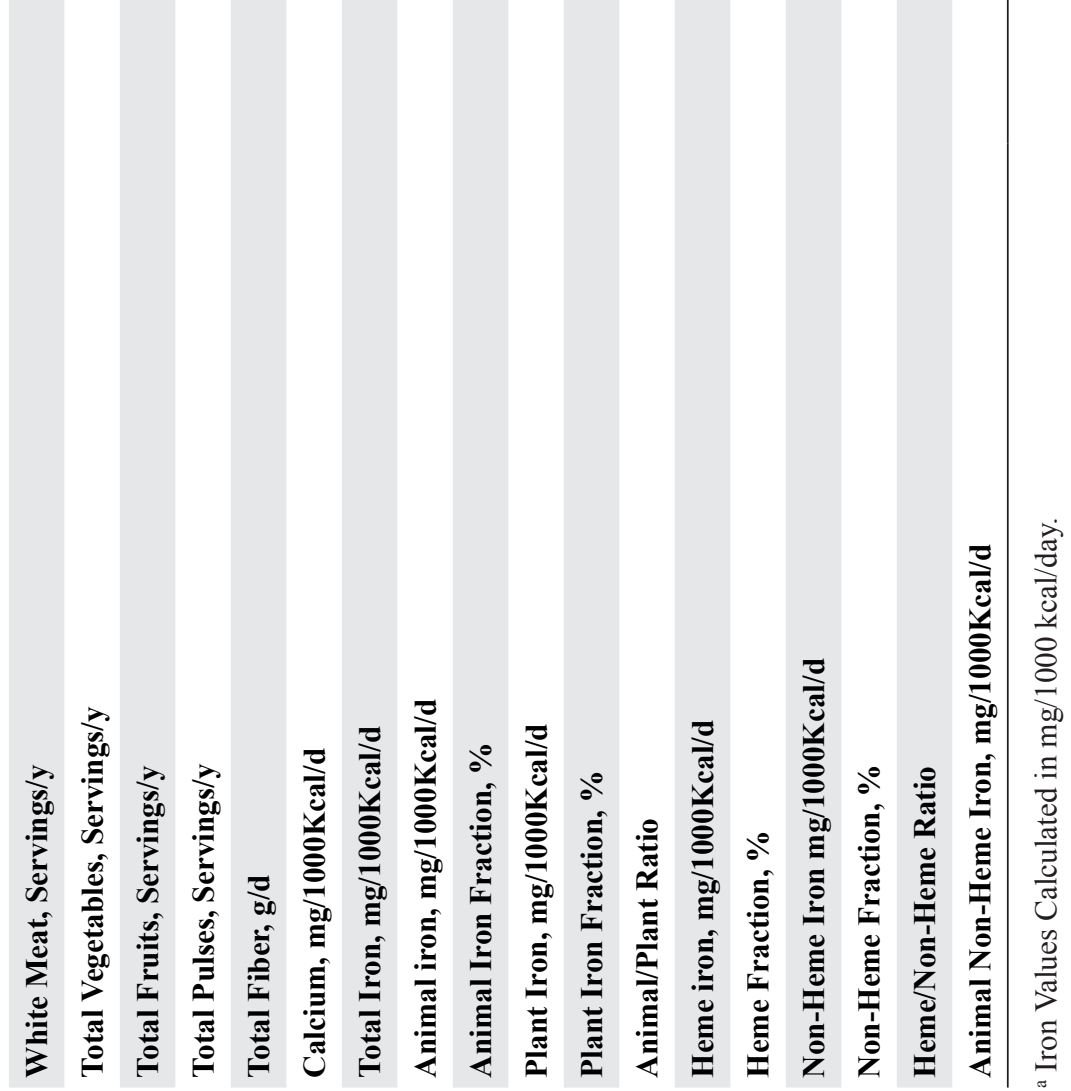


Table 3: Adjusted Odds Ratios (ORs) of Lung Cancer for Dietary Iron: Total, Animal-Based, Plant-Based, Animal/Plant (A/P) Ratio, Heme, Non-Heme, Heme/Non-Heme Ratio (H/NH), Animal NonHeme, and Fractions of Each One From Total Iron ${ }^{\mathrm{a}, \mathrm{b}}$

\begin{tabular}{|c|c|c|}
\hline Iron Variables & OR $(95 \%$ CI $)$ & $\begin{array}{c}\text { Trend } \\
\text { (P Value) }\end{array}$ \\
\hline Total & & $<0.001$ \\
\hline$\leq 3.26$ & $1.00(-)$ & \\
\hline $3.27-3.91$ & $1.54^{\mathrm{c}}(1.15-2.06)$ & \\
\hline $3.92-4.61$ & $1.65^{\mathrm{c}}(1.20-2.28)$ & \\
\hline$\geq 4.62$ & $3.26^{\mathrm{c}}(2.26-4.70)$ & \\
\hline
\end{tabular}

\section{Animal}

$<0.001$

\begin{tabular}{|rr}
\hline$\leq 2.31$ & $1.00(-)$ \\
\hline $2.32-2.93$ & $1.58^{\mathrm{c}}(1.16-2.14)$ \\
\hline $2.94-3.63$ & $1.72^{\mathrm{c}}(1.23-2.42)$ \\
\hline$\geq 3.64$ & $3.73^{\mathrm{c}}(2.49-5.58)$ \\
\hline Animal Fraction & \\
\hline$\leq 69.3$ & $1.00(-)$ \\
\hline $69.4-77.8$ & $1.59^{\mathrm{c}}(1.15-2.18)$ \\
\hline $77.9-84.2$ & $1.85^{\mathrm{c}}(1.30-2.64)$ \\
\hline$\geq 84.3$ & $2.88^{\mathrm{c}}(1.90-4.36)$ \\
\hline
\end{tabular}

Plant 0.057

\begin{tabular}{lr}
\hline$\leq 0.61$ & $1.00(-)$ \\
\hline $0.62-0.87$ & $0.78(0.59-1.02)$ \\
\hline $0.88-1.22$ & $0.81(0.59-1.10)$ \\
$\geq 1.23$ & $0.66^{\mathrm{c}}(0.44-0.97)$
\end{tabular}

Plant Fraction

$<0.001$

$\begin{array}{lr}\leq 15.6 & 1.00(-) \\ 15.7-22.1 & 0.64^{\mathrm{c}}(0.48-0.86) \\ 22.2-30.6 & 0.55^{\mathrm{c}}(0.40-0.76) \\ \geq 30.7 & 0.35^{\mathrm{c}}(0.23-0.53)\end{array}$

Animal/Plant Ratio $<0.001$

$\leq 2.11$

$1.00(-)$

2.12-3.31 $1.59^{\mathrm{c}}(1.14-2.22)$

3.32-5.17 2.06 $(1.43-2.96)$

$\geq 5.18 \quad 3.12^{\mathrm{c}}(2.03-4.80)$

Heme $<0.001$

$\begin{array}{lr}\leq 1.32 & 1.00(-) \\ 1.33-1.74 & 1.34(0.98-1.82) \\ 1.75-2.22 & 1.53^{\mathrm{c}}(1.11-2.12) \\ \geq 2.23 & 2.94^{\mathrm{c}}(2.00-4.32)\end{array}$

Heme Fraction

0.001

$\begin{array}{lr}\leq 39.5 & 1.00(-) \\ 39.6-46.2 & 1.16(0.85-1.58) \\ 46.3-51.6 & 1.55^{\mathrm{c}}(1.12-2.15) \\ \geq 51.7 & 1.78^{\mathrm{c}}(1.23-2.59)\end{array}$

Non Heme $<0.001$

$\begin{array}{lr}\leq 1.77 & 1.00(-) \\ 1.78-2.11 & 1.27(0.96-1.68) \\ 2.12-2.50 & 1.42^{\mathrm{c}}(1.05-1.93) \\ \geq 2.51 & 2.08^{\mathrm{c}}(1.45-2.97)\end{array}$

NonHeme Fraction 0.001

$\begin{array}{lr}\leq 48.3 & 1.00(-) \\ 48.4-53.6 & 0.87(0.66-1.15) \\ 53.7-60.3 & 0.65^{\mathrm{c}}(0.48-0.88) \\ \geq 60.4 & 0.56^{\mathrm{c}}(0.39-0.81)\end{array}$

Heme/Non-Heme Ratio

0.001

$\begin{array}{lr}\leq 0.62 & 1.00(-) \\ 0.63-0.83 & 1.04(0.76-1.43) \\ 0.84-1.05 & 1.42^{\mathrm{c}}(1.02-1.99) \\ \geq 1.06 & 1.72^{\mathrm{c}}(1.18-2.52)\end{array}$

Animal NonHeme

$<0.001$

$\begin{array}{lr}\leq 0.95 & 1.00(-) \\ 0.96-1.16 & 1.46^{\mathrm{c}}(1.07-1.98) \\ 1.17-1.41 & 1.75^{\mathrm{c}}(1.25-2.46) \\ \geq 1.42 & 3.15^{\mathrm{c}}(2.13-4.68)\end{array}$

${ }^{a}$ Regression model including terms for cancer (binary, as dependent variable), age, education years, body mass index, total meat, total plants, total fiber, calcium, cigarette amount, smoking duration years, smoking start, smoking quit, pack-years (continuous); residence, family history of cancer in $1^{\text {st }}$ degree relatives, energy as kilocalories, "maté" intake, alcohol consumption, and cigarette type (categorical) as independent variables.

${ }^{b}$ Includes range values for each category of the analyzed variables. Iron values calculated in mg/1000 kcal/day: total, animal, plant, heme, non-heme, animal heme, and animal non-heme. Animal fraction, plant fraction, heme fraction and non-heme fraction are expressed as a percentage.

c Significant ORs 
compared to controls, respectively. Furthermore, animal iron fraction, APIR, heme iron fraction, and $\mathrm{H} / \mathrm{NH}$ iron fraction were higher among cases. Conversely, controls displayed higher intakes of plant-based iron (0.96 vs. 0.86) and non-heme iron fraction (56.19 vs. 52.91) compared to cases, respectively. Additionally, cases showed higher red meat, pulses, bakery products, and calcium intake. Conversely, controls displayed a higher intake of white meat, total fruits, and fiber. Dietary energy, processed meat, and total vegetables did not show any differences.

Table 3 shows the adjusted ORs of LC and their linear Trends for different iron types. Except for plant-based iron which showed a marginal inverse Trend $(\mathrm{P}=0.057)$, all risk estimations and Trends were significant. Whereas 9/12 estimations ( $75 \%$, mostly related to animal sources) were positively associated with LC risk, the remaining 3 estimations (mainly linked to plant sources) were inversely associated with the incidence of LC. We remarked that the highest quartile of animalbased iron $(>3.6 \mathrm{mg} / 1000 \mathrm{kcal} /$ day $)$ displayed the strongest positive association with the incidence of LC $\left(\mathrm{OR}=3.73\right.$, 95\% CI 2.49-5.58, $\left.\mathrm{P}_{\text {Trend }}<0.001\right)$. In addition, a high plant-based iron fraction $(\geq 30.7 \%)$ was inversely associated with $\mathrm{LC}(\mathrm{OR}=0.35,95 \%$ CI 0.23-0.53, $\left.\mathrm{P}_{\text {Trend }}<0.001\right)$.

Risk estimations for each iron type and main histologic types of LC are presented as continuous ORs in Table 4. Similarly to what was described in the previous Table, a major part of iron variables mostly related to animal sources-, were positively associated with LC risk. Both, positive and inverse associations were found for all cell types.

Table 5 shows continuous ORs of LC for dietary iron after performing analyses by dichotomized strata of smoking intensity and "maté" intake. Most iron variables related to animal sources showed a risk increase for the strata of higher intensity smokers or higher "maté" drinkers. On the other hand, the three iron variables linked to plant sources, tended to show slightly stronger inverse associations among higher consumers of tobacco and "maté". Most of the risk estimations found among higher tobacco and "maté" consumers were statistically significant. However, estimations were not significant among the lower consumers.

Table 6 displays the ORs of LC, related to nonheme iron variables (total non-heme, non-heme fraction and animal non-heme) by strata of the meat types (total, red and processed) which are major contributors in iron level. Each meat type was dichotomized by the median intake. ORs of highest quartile of non-heme iron were significantly high (positively associated) only for the highest intake of the total $(\mathrm{OR}=3.38)$, red $(\mathrm{OR}=2.98)$, and processed meat $(\mathrm{OR}=2.44)$, but not for their lowest intake $(\mathrm{OR}=1.37, \mathrm{OR}=1.37$, and $\mathrm{OR}=1.55$, respectively). Conversely, the non-heme fraction's ORs were significantly low (inversely associated) only for the lowest intake of the total $(\mathrm{OR}=0.47)$, red $(\mathrm{OR}=0.58)$, and processed meat $(\mathrm{OR}=0.39)$, but not for their highest intakes $(\mathrm{OR}=0.71, \mathrm{OR}=0.79$, and $\mathrm{OR}=0.85$, respectively). The highest quartile of animal non-heme iron showed significant positive associations in both strata of all meat types; having always higher ORs in the highest strata of those meat types.

Figure 1 describes a combination of data shown in Table 3. Risk classification is suggested according to the respective iron percentages from plant and animal sources with estimations made based on midpoints in each intake category. Animal nonheme iron was calculated as previously explained, through subtracting heme iron from animal iron. Looking for correspondences with data on Table 3, when the animal iron, heme iron, and APIR were increased, the ORs were amplified as well. The same happened when plant iron decreased.

\section{DISCUSSION}

The present analysis is the first study on dietary iron and LC risk conducted in a Latin American country where epidemiologic features (highest LC incidence rates of America, highest meat and "maté" intake of the world) deserve to explore possible associations between the disease and iron intake.

All variables which assess dietary iron displayed significant associations with LC risk when comparing the highest vs. the lowest quartile, most of them positively associated and very few inversely associated. The highest total iron intake was positively associated with $\mathrm{LC}$ risk $(\mathrm{OR}=3.26$, 95\% CI 2.26-4.70, $\mathrm{P}_{\text {Trend }}<0.001$ ). This differs with the findings of Ward et al., [30] where total iron lacked association with risk of LC incidence, and also differs with the study of Mahabir et al., [25] who reported a protective effect for the whole study population, even slightly better among women. 


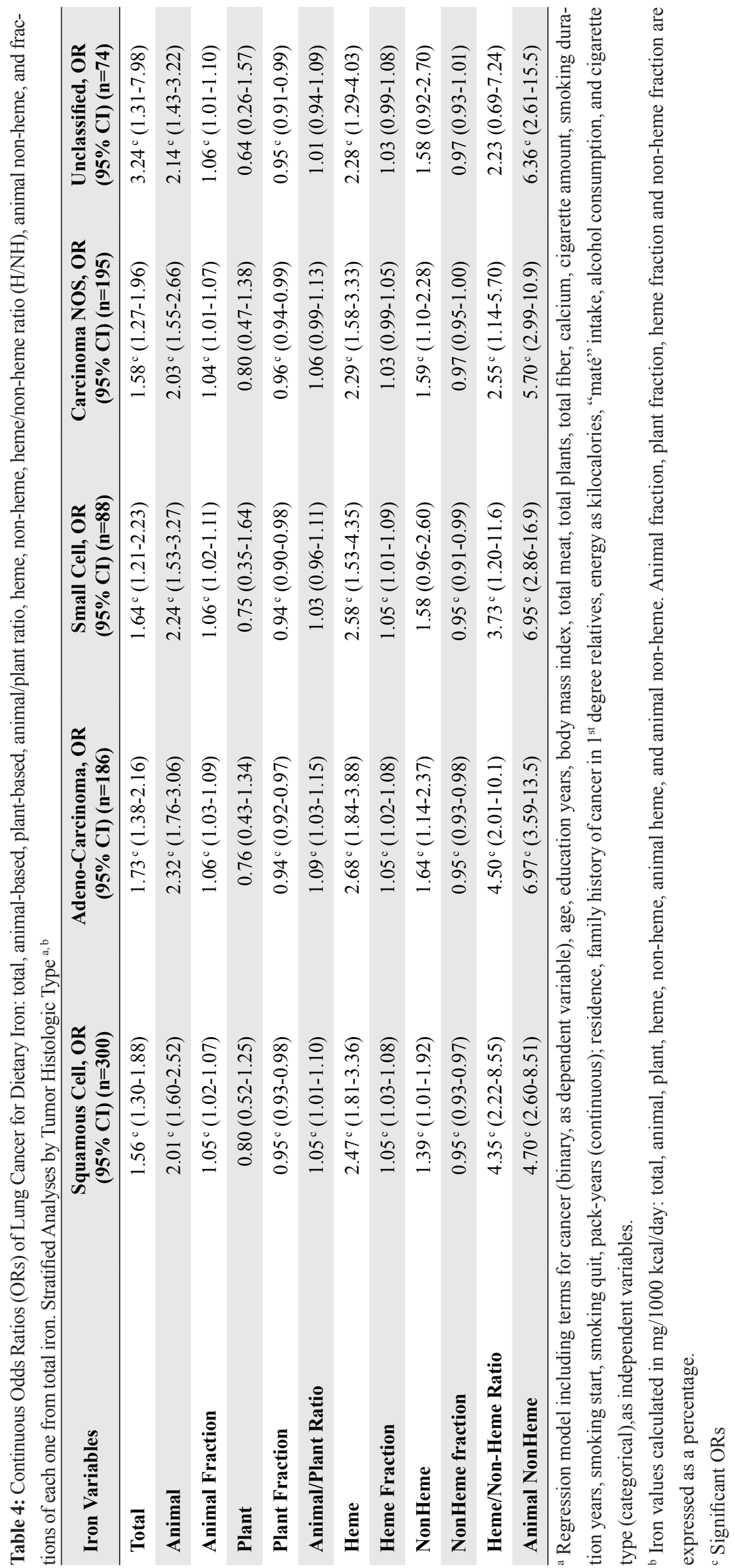




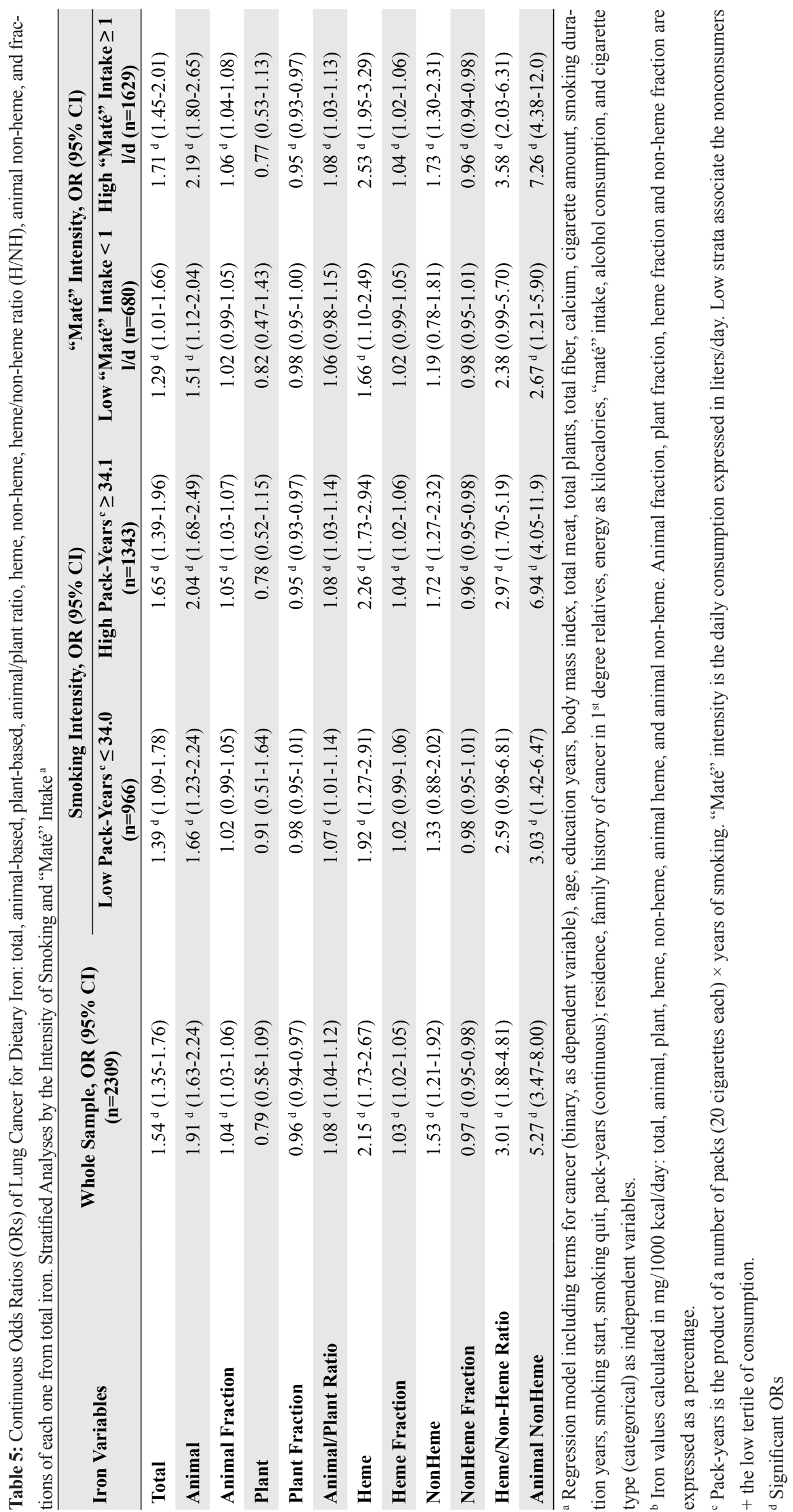




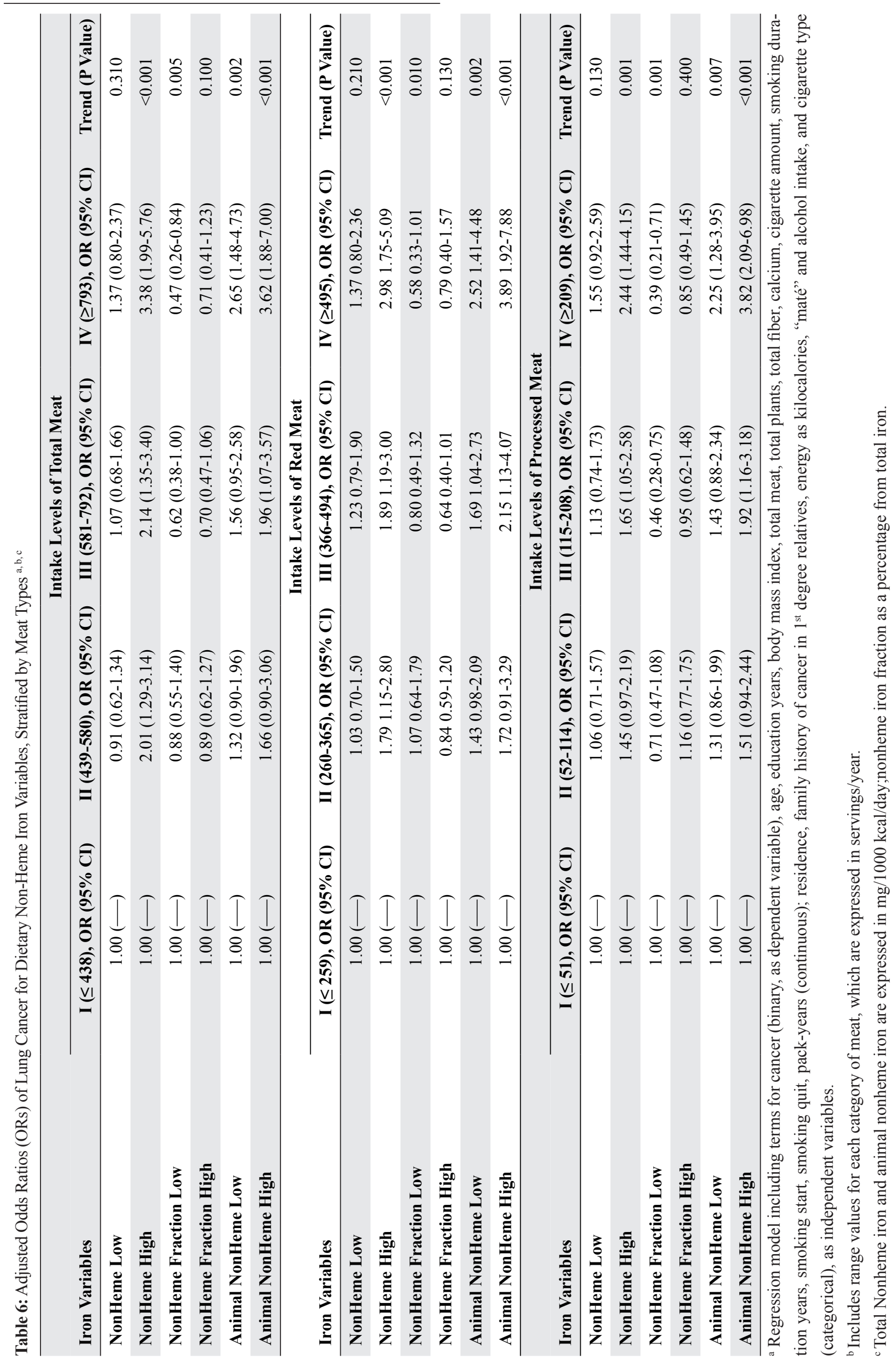




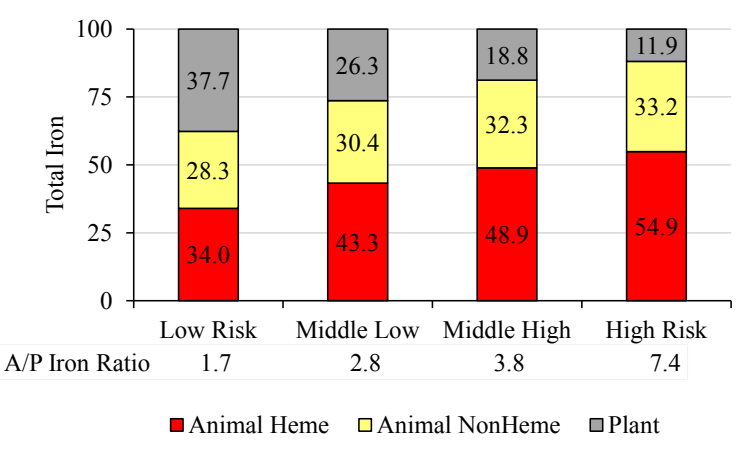

Figure 1: Graphic Expression of Results, Based on a Combination of Selected Data From Table 3

Regarding animal/plant ratio, the putative risk categories correspond to those appearing in the quoted Table. The existing differences between Table and Figure depend on a herewith calculation, done based on midpoint values of each category. For example, the animal/plant ratio in the first quartile (reference category) was $\leq 2.11$ and for the Figure is 1.65 . On the other hand, the highest quartile in the Table showed an animal/plant ratio of $\geq 5.18$ and for the Figure is 7.40 .

High heme iron intake showed the strongest association with $\mathrm{LC}(\mathrm{OR}=3.73,95 \%$ CI 2.49-5.58, $\left.\mathrm{P}_{\text {Trend }}<0.001\right)$. The risk increase for heme iron intake and LC is compatible with some studies $[24,28,30]$ but differs from other reports [25$27,29]$. Non-heme iron intake was found to be directly associated with $\mathrm{LC}(\mathrm{OR}=2.08,95 \%$ CI $1.45-2.97, \mathrm{P}_{\text {Trend }}<0.001$ ) which is in agreement with the study of Zhou et al., [29] who also found an inverse association for heme iron intake and LC. It can be hypothesized that a potentially beneficial role of heme iron intake might be attributed to other animal dietary sources. However, the exact mechanistic explanation for the protective effect of heme iron has remained unclear.

Comparability among reports is somehow limited due to their different methodologies as well as dissimilar analyzed groups. Inconsistency of results between studies may be also due to different levels of dietary intake of minerals (including iron intake) across studies. In addition, the inclusion of dietary vitamin $\mathrm{C}$ (a facilitator of heme iron absorption) or HCA (carcinogens derived from the cooking method) in the regression models can generate differences among studies. Results reported by Lee et al., [24] were derived from a study in women, whereas our study was performed in men population. In the present study, we found opposite trends for high intakes of iron from animal and plant sources $(\mathrm{OR}=3.73$ vs. $\mathrm{OR}=0.66$, respectively) which was also expressed as an animal/plant ratio
$(\mathrm{OR}=3.12$ for the highest quartile). In addition, when considering their respective fractions from total iron, we found that $\geq 84.3 \%$ of animal iron was directly associated with an increased risk of $\mathrm{LC}\left(\mathrm{OR}=2.88, \mathrm{P}_{\text {Trend }}<0.001\right)$. From the viewpoint of plant sources, when plant iron was $\geq 30.7 \%$, there was a strong inverse association between these two variables $\left(\mathrm{OR}=0.35, \mathrm{P}_{\text {Trend }}<0.001\right)$.

Results coming from the heme or non-heme sources appeared not so clear, indeed. Estimates of LC incidence were positively associated with high intake of heme iron $\left(\mathrm{OR}=2.94, \mathrm{P}_{\text {Trend }}<0.001\right)$ as well as for non-heme iron $\left(\mathrm{OR}=2.08, \mathrm{P}_{\text {Trend }}<0.001\right)$. $\mathrm{H} / \mathrm{NH}$ ratio was also directly associated with LC $\left(\mathrm{OR}=1.72, \mathrm{P}_{\text {Trend }}<0.001\right)$. Furthermore, their respective fractions displayed opposite associations: While $\geq 51.7 \%$ of heme iron was directly associated with $\mathrm{LC}\left(\mathrm{OR}=1.78, \mathrm{P}_{\text {Trend }}<0.001\right)$, a high fraction of non-heme iron $(\geq 60.4 \%)$ was inversely associated with LC $\left(\mathrm{OR}=0.56, \mathrm{P}_{\text {Trend }}<0.001\right)$. We think that further analysis the results of which are presented in Table 6 shed some light to this point: low intake of non-heme iron within low meat intake strata (total, red and processed) did not show a significant relationship with LC, whereas a significantly increased risks of LC was detected in patients with high meat intakes. At the same time, non-heme fraction -which was generally protective- lost its significance in patients with high meat intake, but it did not differ in those with low meat intake.

Since animal foods -mainly red and processed meat- contain some non-heme iron, we thought that differences between ORs of plant and non-heme iron might be explained through estimation of such non-heme iron derived from animal sources. The latter was then calculated by the formula already described in the Methods section. This iron type also showed positive associations with LC risk (OR for highest quartile=3.15, $\mathrm{P}_{\text {Trend }}<0.001$ ).

Analyses performed on each cell type did not show remarkable differences among them. Significant risk increases for squamous cell, adenocarcinoma, small cell, carcinoma, and unclassified cancers were observed for total iron, animal iron, heme iron, and most of their derived variables. Plant and non-heme iron tended to show different associations, just as the observed ones for highest quartiles in the whole sample, but not among cell types. Our observations showed some coincidences and differences with previous studies. On one 
hand, Ward et al., [30] reported a significant risk increase for heme iron in patients with small cell carcinomas. On the other hand, Muka et al., [26] found no risk differences regarding total iron intake and subtypes of LC. In fact, all subtypes tended to be associated in a protective sense. Zhou et al., [29] reported risk increase for total iron on squamous cell and adenocarcinoma subtypes.

We have done additional analyses on strata of smoking intensity and daily intake of "maté" infusion, which is presented in Table 5. Regarding the smoking intensity, the continuous ORs were slightly higher for potential risk variables and slightly lower for potential protective variables in a high-intensity category ( $\geq 34.1$ pack-years). The same was observed among high "maté" drinkers $(\geq 1$ liter/day). Both habits involve potential biochemical links to cancer and iron metabolism which add complexity to any analysis.

Dimethylbenz[a]anthracene (DMBA) -an environmental contaminant that participates in generating several oxidative stress-mediated diseases, including cancer- should be considered regarding its links with LC since it is present in barbequed meat, tobacco smoke, and overheated cooking oil [46]. Unlike the hot temperature of "maté" -accepted as a risk factor for upper aerodigestive tract cancers [47]-, the quoted components could be partially responsible for the association with cancer in organs which have no direct contact with the beverage such as lungs and genitourinary organs [37]. Interestingly, DMBA, like $\mathrm{BaP}$, is also an indirect-acting carcinogen, requiring metabolic activation to yield its ultimate carcinogenic form [48], in particular, oxidation by CYP enzymes [49].

Free iron is known to play an important role in generating hydroxyl radicals in oxidative stress, which can directly attack biomolecules such as DNA, protein, and lipids [50]. The nonsignificant inverse associations of plant iron and its fractions, described in Table 5, are highly similar in both strata of "maté" drinkers. Concerning strata of smoking intensity, most iron types experienced modest increases in their continuous risks for the highest category ( $\geq 34.1$ pack-years), mainly among some animal-based iron variables. Most of these estimates showed a significant association with the incidence of LC. Conversely, no remarkable differences were observed for plant-based iron variables and risk of LC.

Cigarette smoke contains iron particulates and toxic substances that can induce intracellular iron accumulation and alter iron homeostasis in the lung and as well as its systemic effects [51, 52]. A potential relationship between iron accumulation and inflammation in the progression of cigarette smoking-associated diseases -such as COPD and LC- has been suggested [15].

Observations suggest that when subjects have a regular diet low in plant-based foods, potential antioxidant compounds found in "maté" infusion could be counterbalanced and also overcome by its own pro-carcinogenic compounds. There is considerable epidemiologic support for the benefits of consuming plants (mainly fruits and vegetables) rich in antioxidants, in particular, polyphenols, since most polyphenolic compounds (e.g. flavones, anthocyanidins) have not only antioxidant properties, but they may also chelate iron $[53,54]$. "Maté" can be included into this combined category, according to a recent study on healthy subjects receiving ferrous sulfate, showed that "maté" infusion reduced $\sim 76 \%$ of the non-heme iron absorption [55]. Theoretically, modulating iron absorption could be convenient for individuals who have the habit of taking a meat-rich diet. Iron-chelating compounds possess anti-cancer activity, an effect largely attributed to ribonucleotide reductase inhibition in proliferating cells [56]. Nevertheless, potential protection linked to additional antioxidant load coming from plant sources (including vegetables, fruits, legumes and eventually tea infusions) is not likely to be expected in the present study, since analyzed subjects were not high plant foods consumers.

Dietary styles of cases and controls deserve some additional comments. Differences in iron intake are mostly attributed to red/processed meat intake by LC cases. The control group had very high red meat intake ( $\sim 1$ serving/day) which was far from usual healthy recommendations. Processed meat intake was not different between cases and controls but the mean intake was high ( $\sim 3$ servings/ week). Among cases, red meat intake overcame vegetable intake in 50\% (441/294 servings/year, respectively) and fruit intake in $15 \%$ of participants (441/385 servings/year, respectively). White meat (fish+chicken) intake was significantly lower among cases. Finally, cases also showed higher 
alcohol and "maté" intake.

From the viewpoint of iron intake, if dietary changes reduce red and processed meat consumption, while increases the intake of vegetables and fruits, animal iron would be reduced and plant iron consumption would increase. Results suggest that the best proportions of iron intake would be $<69 \%$ of animal origin and $>31 \%$ of plant origin. Taking into account that energy intake was very similar for cases and controls, the selected items suggest that the dietary style of LC cases is far from being a healthy one, nevertheless, such style is modifiable looking for the achievement of a modest reduction in LC risk.

Our investigation has some limitations and strengths which are commonplace in case-control studies. Among the limitations, we recognized the lack of a validated questionnaire, although the instrument was tested for reproducibility and showed high correlations [34]. The validation was projected to be done, but due to sudden budgetary cuts, which took place in the early 2000s-reflecting the most severe financial crisis in the story of Uruguayit has never been performed later. Epidemiologic research on cancer in Uruguay continued with the remaining databases-like the one used for the present study - and without funds to update or improve them.

Another limitation was related to iron intake estimations. They might not have been as accurate as desirable because they were based on average serving sizes and not on actual food sizes. Iron supplements were not part of the FFQ. We cannot exclude the role of confounders by other dietary factors, such as other constituents of animal foods or the effects of different cooking methods.

Additional pathological information on epidermal growth factor receptor (EGFR) mutation would have been useful to analyze, nevertheless, such data were unavailable at the time of interviews, therefore we were unable to make deeper analyses looking for interrelationships among dietary iron and those molecular items. EGFR is a modulator of cellular iron homeostasis through promoting increased cell surface expression of Transferrin Receptor 1 which is essential for cancer development and progression [57]. Assessing potential links between EGFR with iron types is something to be considered in future research. LC has currently high incidence among Uruguayan women and it is rising, but during the years of data collection, women cases constituted a very small sample to be analyzed. Therefore, comparisons with men were not possible to be done. They would have been very useful regarding their biologically different iron level management during adulthood. As the strengths of the study, the analyzed population included subsets coming from the whole country, and times of data collection were coincident. Although age matching was not perfect, the distribution was adequate; also matching by the urban/rural residence and country region gave homogeneity to the analyzed sample. The potential for selection bias exists in our study, as in any case-control study, but it is unlikely to have substantial effects on our results due to the overall high participation rates achieved in this study $(\sim 97 \%)$. Since data collection was done until 2004, no effect from wheat flour fortification with iron (established by law in $30 \mathrm{mg} / \mathrm{kg}$ at a national level in 2005) is expected in the population sample of the current study. A thorough adjustment performed by eight tobacco smoking variables is another strength, allowing us to reduce a potential residual confounding effect which was difficult to be completely ruled out. Although it is unlikely to completely avoid any kind of bias, we think that the results of the present study were not chance findings.

In conclusion, our study demonstrates consistent associations of dietary iron with LC risk. This applies for total iron and also for both heme and nonheme subtypes; suggesting that the animal source is more relevant to increased risk of LC; while plant source was found to decrease such risks. Further epidemiologic and mechanistic research is needed to disentangle complex nutritional and biochemical interrelationships linked to the disease.

\section{ACKNOWLEDGMENTS}

We thank Nutritionist Estela Abbona, for her technical review of the manuscript.

\section{CONFLICT OF INTEREST}

None to be declared.

\section{ETHICS APPROVAL}

The study was conducted after receiving the approval of each Medical Director belonging to the involved hospitals, following an ethical approval in each participant institution. For 
this type of studies and during the years when interviews were performed, patients did not sign the informed consent, since it was not mandatory for interviewers. The participants were assured regarding the obvious condition of confidentiality for the individual's data before the interviews.

\section{REFERENCES}

1. Honorary Committee Against Cancer. National Cancer Registry of Uruguay. Incidence and Mortality 2011-2015. Montevideo: Honorary Committee Against Cancer; [cited 2019 Jul 28]. Available from: http://www.comisioncancer. org.uy/hnnoticiaj1.aspx?209,53.

2. Bray F, Ferlay J, Soerjomataram I, Siegel RL, Torre LA, Jemal A. Global cancer statistics 2018: GLOBOCAN estimates of incidence and mortality worldwide for 36 cancers in 185 countries. CA Cancer J Clin. 2018;68(6):394-424. DOI: $10.3322 /$ caac.21492 PMID: 30207593.

3. Danaei G, Vander Hoorn S, Lopez AD, Murray CJ, Ezzati $\mathrm{M}$. Causes of cancer in the world: comparative risk assessment of nine behavioural and environmental risk factors Lancet. 2005;366(9499):1784-93. DOI: 10.1016/s01406736(05)67725-2 PMID: 16298215.

4. Malhotra J, Malvezzi M, Negri E, La Vecchia C, Boffetta P. Risk factors for lung cancer worldwide. Eur Respir J. 2016;48(3):889-902. DOI: 10.1183/13993003.00359-2016 PMID: 27174888.

5. Deneo-Pellegrini H, De Stefani E, Ronco A, Mendilaharsu M, Carzoglio JC. Meat consumption and risk of lung cancer; a case-control study from Uruguay. Lung Cancer. 1996;14(2):195-205. DOI: https://doi.org/10.1016/01695002(95)00546-3.

6. De Stefani E, Boffetta P, Ronco AL, Deneo-Pellegrini H, Acosta G, Gutierrez LP, et al. Nutrient patterns and risk of lung cancer: a factor analysis in Uruguayan men. Lung Cancer. 2008;61(3):283-91. DOI: 10.1016/j.lungcan.2008.01.004 PMID: 18295929.

7. Deneo-Pellegrini H, Ronco AL, De Stefani E. Meat consumption and risk of squamous cell carcinoma of the lung: a case-control study in Uruguayan men. Nutr Cancer. 2015;67(1):82-8. DOI: 10.1080/01635581.2015.970290 PMID: 25411912.

8. Food and Agriculture Organization. FAO; 2019 [cited 2019 Jul 28]. Available from: http://www.fao.org/faostat/ en/\#data/CL.

9. World Cancer Research Fund/American Institute for Cancer Research. Food, nutrition, physical activity, and the prevention of cancer: a global perspective. Washington DC: AICR, 2007.

10. Gnagnarella P, Caini S, Maisonneuve P, Gandini S. Carcinogenicity of High Consumption of Meat and Lung Cancer Risk Among Non-Smokers: A Comprehensive Meta-Analysis. Nutr Cancer. 2018;70(1):1-13. DOI: 10.1080/01635581.2017.1374420 PMID: 29016198.

11. Manz DH, Blanchette NL, Paul BT, Torti FM, Torti SV. Iron and cancer: recent insights. Ann N Y Acad Sci. 2016;1368(1):149-61. DOI: 10.1111/nyas.13008 PMID:
26890363.

12. Hooda J, Shah A, Zhang L. Heme, an essential nutrient from dietary proteins, critically impacts diverse physiological and pathological processes. Nutrients. 2014;6(3):1080102. DOI: $10.3390 /$ nu6031080 PMID: 24633395.

13. Coffey R, Ganz T. Iron homeostasis: An anthropocentric perspective. J Biol Chem. 2017;292(31):12727-34. DOI: 10.1074/jbc.R117.781823 PMID: 28615456.

14. Neves J, Haider T, Gassmann M, Muckenthaler MU. Iron Homeostasis in the Lungs-A Balance between Health and Disease. Pharmaceuticals (Basel). 2019;12(1). DOI: 10.3390/ph12010005 PMID: 30609678.

15. Ali MK, Kim RY, Karim R, Mayall JR, Martin KL, Shahandeh A, et al. Role of iron in the pathogenesis of respiratory disease. Int J Biochem Cell Biol. 2017;88:181-95. DOI: 10.1016/j.biocel.2017.05.003 PMID: 28495571.

16. Fonseca-Nunes A, Jakszyn P, Agudo A. Iron and cancer risk--a systematic review and meta-analysis of the epidemiological evidence. Cancer Epidemiol Biomarkers Prev. 2014;23(1):12-31. DOI: 10.1158/1055-9965.epi-13-0733 PMID: 24243555.

17. Wang Y, Yu L, Ding J, Chen Y. Iron Metabolism in Cancer. Int J Mol Sci. 2019;20:95. DOI: 10.3390/ijms20010095.

18. Wen CP, Lee JH, Tai YP, Wen C, Wu SB, Tsai MK, et al. High serum iron is associated with increased cancer risk. Cancer Res. 2014;74(22):6589-97. DOI: 10.1158/00085472.can-14-0360 PMID: 25228650.

19. Sukiennicki GM, Marciniak W, Muszynska M, Baszuk P, Gupta S, Bialkowska K, et al. Iron levels, genes involved in iron metabolism and antioxidative processes and lung cancer incidence. PLoS One. 2019;14(1):e0208610. DOI: 10.1371/journal.pone.0208610 PMID: 30640897.

20. Chen HF, Wu LX, Li XF, Zhu YC, Wang WX, Xu CW, et al. A meta-analysis of association between serum iron levels and lung cancer risk. Cell Mol Biol (Noisy-le-grand). 2018;64(13):33-7. PMID: 30403607.

21. Quintana Pacheco DA, Sookthai D, Graf ME, Schubel R, Johnson T, Katzke VA, et al. Iron status in relation to cancer risk and mortality: Findings from a population-based prospective study. Int J Cancer. 2018;143(3):561-9. DOI: 10.1002/ijc.31384 PMID: 29574909.

22. Ronco AL, Calderon JM, Espinosa E. Dietary Iron, 'Mate' Intake and Breast Cancer Risk: A Case-Control Study in Uruguay. J Breast Cancer Res Adv. 2017;1(1):1-7. DOI: 10.16966/2638-3527.102.

23. Ronco AL, Espinosa E, Calderón JM. A case-control study on heme/non-heme iron and breast cancer risk. Ann Clin Nutr. 2018;3:1011.

24. Lee DH, Jacobs DR, Jr. Interaction among heme iron, zinc, and supplemental vitamin $\mathrm{C}$ intake on the risk of lung cancer: Iowa Women's Health Study. Nutr Cancer. 2005;52(2):130-7. DOI: 10.1207/s15327914nc5202_ 3 PMID: 16201844.

25. Mahabir S, Forman MR, Dong YQ, Park Y, Hollenbeck A, Schatzkin A. Mineral intake and lung cancer risk in the NIH-American Association of Retired Persons Diet and Health study. Cancer Epidemiol Biomarkers Prev. 2010;19(8):1976-83. DOI: 10.1158/1055-9965.epi-10- 
0067 PMID: 20696660.

26. Muka T, Kraja B, Ruiter R, Lahousse L, de Keyser CE, Hofman A, et al. Dietary mineral intake and lung cancer risk: the Rotterdam Study. Eur J Nutr. 2017;56(4):1637-46. DOI: 10.1007/s00394-016-1210-4 PMID: 27073037.

27. Tasevska N, Cross AJ, Dodd KW, Ziegler RG, Caporaso NE, Sinha R. No effect of meat, meat cooking preferences, meat mutagens or heme iron on lung cancer risk in the prostate, lung, colorectal and ovarian cancer screening trial. Int J Cancer. 2011;128(2):402-11. DOI: 10.1002/ijc.25327 PMID: 20232386.

28. Tasevska N, Sinha R, Kipnis V, Subar AF, Leitzmann MF, Hollenbeck AR, et al. A prospective study of meat, cooking methods, meat mutagens, heme iron, and lung cancer risks. Am J Clin Nutr. 2009;89(6):1884-94. DOI: 10.3945/ ajcn.2008.27272 PMID: 19369370.

29. Zhou W, Park S, Liu G, Miller DP, Wang LI, Pothier L, et al. Dietary iron, zinc, and calcium and the risk of lung cancer. Epidemiology. 2005;16(6):772-9. PMID: 16222167.

30. Ward HA, Whitman J, Muller DC, Johansson M, Jakszyn P, Weiderpass E, et al. Haem iron intake and risk of lung cancer in the European Prospective Investigation into Cancer and Nutrition (EPIC) cohort. Eur J Clin Nutr. 2018. DOI: 10.1038/s41430-018-0271-2 PMID: 30337714.

31. Honorary Committee Against Cancer. [Knowledge, beliefs, attitudes and practices related to cancer: population survey. Technical cooperation PNUD/BID] Montevideo: Honorary Committee Against Cancer; 1993 [cited 2019 Jul 28]. Available from: http://www.comisioncancer.org.uy/ categoria_53 1.html.

32. International Agency for Research on Cancer. Coffee, tea, mate, methylxanthines and methylglyoxal. IARC Working Group on the Evaluation of Carcinogenic Risks to Humans. IARC Monogr Eval Carcinog Risks Hum. 1991;51:273-87. PMID: 1674554.

33. Kamangar F, Schantz MM, Abnet CC, Fagundes RB, Dawsey SM. High levels of carcinogenic polycyclic aromatic hydrocarbons in mate drinks. Cancer Epidemiol Biomarkers Prev. 2008;17(5):1262-8. DOI: 10.1158/10559965.epi-08-0025 PMID: 18483349.

34. Thea AE, Ferreira D, Brumovsky LA, Schmalko ME. Polycyclic aromatic hydrocarbons (PAHs) in yerba maté (Ilex paraguariensis St. Hil) traditional infusions (mate and tereré). Food Control. 2016;60:215-20. DOI: 10.1016/j.foodcont.2015.07.046.

35. International Agency for Research on Cancer. Some non-heterocyclic polycyclic aromatic hydrocarbons and some related exposures. IARC Working Group on the Evaluation of Carcinogenic Risks to Humans. IARC Monogr Eval Carcinog Risks Hum. 2010;92:1-853. PMID: 21141735.

36. De Stefani E, Fierro L, Correa P, Fontham E, Ronco A, Larrinaga $\mathrm{M}$, et al. Mate drinking and risk of lung cancer in males: a case-control study from Uruguay. Cancer Epidemiol Biomarkers Prev. 1996;5(7):515-9. PMID: 8827355.

37. Stefani ED, Moore M, Aune D, Deneo-Pellegrini H, Ronco AL, Boffetta $P$, et al. Mate consumption and risk of cancer: a multi-site case-control study in Uruguay. Asian Pac J Cancer Prev. 2011;12(4):1089-93. PMID: 21790257.
38. Dupont WD. Power calculations for matched case-control studies. Biometrics. 1988;44(4):1157-68. PMID: 3233252.

39. Breslow NE, Day NE. Statistical methods in cancer research. Vol. 1. The analysis of case-control studies. Geneva, Switzerland: World Health Organization, IARC Scientific Publications; 1980. 5-338 p.

40. Granmo sample size and power calculator, version 7.11 Barcelona, Spain: IMIM; [cited 2019 Jul 28]. Available from: https://www.imim.cat/ofertadeserveis/en granmo.html.

41. Ronco AL, De Stefani E, Boffetta P, Deneo-Pellegrini $H$, Acosta G, Mendilaharsu M. Food patterns and risk of breast cancer: A factor analysis study in Uruguay. Int J Cancer. 2006;119(7):1672-8. DOI: 10.1002/ijc.22021 PMID: 16708380.

42. Mazzei ME, Puchulu MR, Rochaix MA. [Table of food chemical composition]. 2nd ed. Buenos Aires: Cenexa y Feiden Publishers; 1995.

43. Zhang W, Iso H, Ohira T, Date OC, Tanabe N, Kikuchi $\mathrm{S}$, et al. Associations of dietary iron intake with mortality from cardiovascular disease: the JACC study. J Epidemiol. 2012;22(6):484-93. DOI: 10.2188/jea.je20120006 PMID: 22986645.

44. Balder HF, Vogel J, Jansen MC, Weijenberg MP, van den Brandt PA, Westenbrink S, et al. Heme and chlorophyll intake and risk of colorectal cancer in the Netherlands cohort study. Cancer Epidemiol Biomarkers Prev. 2006;15(4):717-25. DOI: 10.1158/1055-9965.epi-05-0772 PMID: 16614114.

45. Kabat GC, Miller AB, Jain M, Rohan TE. A cohort study of dietary iron and heme iron intake and risk of colorectal cancer in women. Br J Cancer. 2007;97(1):118-22. DOI: 10.1038/sj.bjc.6603837 PMID: 17551493.

46. Tiwari P, Sahay S, Pandey M, Qadri SS, Gupta KP. Combinatorial chemopreventive effect of butyric acid, nicotinamide and calcium glucarate against the 7,12-dimethylbenz(a)anthracene induced mouse skin tumorigenesis attained by enhancing the induction of intrinsic apoptotic events. Chem Biol Interact. 2015;226:1-11. DOI: 10.1016/j. cbi.2014.11.018 PMID: 25478867.

47. Lubin JH, De Stefani E, Abnet CC, Acosta G, Boffetta P, Victora $\mathrm{C}$, et al. Mate drinking and esophageal squamous cell carcinoma in South America: pooled results from two large multicenter case-control studies. Cancer Epidemiol Biomarkers Prev. 2014;23(1):107-16. DOI: 10.1158/10559965.epi-13-0796 PMID: 24130226.

48. Badal S, Delgoda R. Role of the modulation of CYP1A1 expression and activity in chemoprevention. J Appl Toxicol. 2014;34(7):743-53. DOI: 10.1002/jat.2968 PMID: 24532440.

49. Szaefer H, Krajka-Kuzniak V, Ignatowicz E, Adamska T, Markowski J, Baer-Dubowska W. The effect of cloudy apple juice on hepatic and mammary gland phase I and II enzymes induced by DMBA in female Sprague-Dawley rats. Drug Chem Toxicol. 2014;37(4):472-9. DOI: 10.3109/01480545.2014.893442 PMID: 24580095.

50. McCord JM. Iron, free radicals, and oxidative injury. Semin Hematol. 1998;35(1):5-12. PMID: 9460805.

51. Ghio AJ, Hilborn ED, Stonehuerner JG, Dailey LA, Car- 
ter JD, Richards JH, et al. Particulate matter in cigarette smoke alters iron homeostasis to produce a biological effect. Am J Respir Crit Care Med. 2008;178(11):1130-8. DOI: $10.1164 / \mathrm{rccm} .200802-3340 \mathrm{C}$ PMID: 18723436.

52. Zhang WZ, Butler JJ, Cloonan SM. Smoking-induced iron dysregulation in the lung. Free Radic Biol Med. 2019;133:238-47. DOI: 10.1016/j.freeradbiomed.2018.07.024 PMID: 30075191.

53. Morel I, Lescoat G, Cogrel P, Sergent O, Pasdeloup N, Brissot $\mathrm{P}$, et al. Antioxidant and iron-chelating activities of the flavonoids catechin, quercetin and diosmetin on iron-loaded rat hepatocyte cultures. Biochem Pharmacol. 1993;45(1):13-9. DOI: 10.1016/0006-2952(93)90371-3 PMID: 8424806.

54. Souza AHP, Correa RCG, Barros L, Calhelha RC, Santos-Buelga C, Peralta RM, et al. Phytochemicals and bioactive properties of Ilex paraguariensis: An in-vitro comparative study between the whole plant, leaves and stems. Food Res Int. 2015;78:286-94. DOI: 10.1016/j. foodres.2015.09.032 PMID: 28433294.

55. Colpo AC, Rosa H, Lima ME, Pazzini CE, de Camargo VB, Bassante FE, et al. Yerba mate (Ilex paraguariensis St. Hill.)-based beverages: How successive extraction influences the extract composition and its capacity to chelate iron and scavenge free radicals. Food Chem. 2016;209:185-95. DOI: 10.1016/j.foodchem.2016.04.059 PMID: 27173551.

56. Fryknas M, Zhang X, Bremberg U, Senkowski W, Olofsson $\mathrm{MH}$, Brandt $\mathrm{P}$, et al. Iron chelators target both proliferating and quiescent cancer cells. Sci Rep. 2016;6:38343. DOI: 10.1038/srep38343 PMID: 27924826.

57. Wang B, Zhang J, Song F, Tian M, Shi B, Jiang H, et al. EGFR regulates iron homeostasis to promote cancer growth through redistribution of transferrin receptor 1 . Cancer Lett. 2016;381(2):331-40. DOI: 10.1016/j.canlet.2016.08.006 PMID: 27523281. 